\title{
Ceramic Material based Optical Antenna for Multiband Photonics Applications
}

\section{Anand Sharma ( $\square$ anandsharma@mnnit.ac.in)}

Motilal Nehru National Institute of Technology https://orcid.org/0000-0001-8566-1710

\section{Yogendra Kumar Prajapati}

Motilal Nehru National Institute of Technology

\section{Devendra Kumar Tripathi}

Rajkiya Engineering College Sonbhadra

\section{Research Article}

Keywords: Optical Antenna, Multi Resonance, Hybrid Mode, Broadsided Radiation Pattern

Posted Date: June 4th, 2021

DOI: https://doi.org/10.21203/rs.3.rs-547310/v1

License: (c) (1) This work is licensed under a Creative Commons Attribution 4.0 International License.

Read Full License

Version of Record: A version of this preprint was published at Optical Engineering on January 31st, 2022. See the published version at https://doi.org/10.1117/1.0E.61.1.017104. 


\title{
Ceramic Material based Optical Antenna for Multiband Photonics Applications
}

\author{
Anand Sharma ${ }^{1}$, Yogendra Kumar Prajapati ${ }^{1}$, Devendra Kumar Tripathi ${ }^{2}$ \\ ${ }^{1}$ Department of Electronics \& Communication Engineering, Motilal Nehru National Institute \\ of Technology Allahabad, Prayagraj, Uttar Pradesh, India - 211004 \\ ${ }^{2}$ Department of Electronics Engineering, Rajkiya Engineering College, Sonbhadra, Uttar \\ Pradesh, India - 231206 \\ anandsharma@mnnit.ac.in,yogendrapra@mnnit.ac.in,dekt@rediffmail.com
}

\begin{abstract}
In this article, design and development of a multiband ceramic materialbased Optical antenna is discussed. Square shaped aperture is utilized to excited silicon based dielectric resonator. This type of excitation system provides the capability to create triple hybrid mode $\left(\mathrm{HEM}_{11 \delta}, \mathrm{HEM}_{12 \delta}\right.$ and $\left.\mathrm{HEM}_{11 \delta+2}\right)$ inside the cylindrical shaped ceramic material. Due to this feature, the proposed aerial is operating over diverse frequency bands i.e. 117.5-140 THz, 158-165.5 $\mathrm{THz}$ and 175.2-190.5 THz respectively. Stable radiation characteristics as well as good value of gain (about 4.0 dBi) makes the proposed Nano-radiator applicable for hyper spectral imaging system (125 THz) and VLC for wireless LAN (160/180THz).
\end{abstract}

Keywords-Optical Antenna, Multi Resonance, Hybrid Mode, Broadsided Radiation Pattern

\section{INTRODUCTION}

In the recent years, the main development in field of nanotechnology is the design and analysis of antennas in optical domain. There are wide used of optical antennas such as, imaging, biosensors, optical transmitter as well as receiver [1-3]. It is also used as feeding technique for waveguide and transmission line at optical spectrum [4-6]. Optical antenna, in general, is downscaled version of radiators in RF domain. But, the design procedure is not as easy as said. There are large number of challenges occurs as the frequency of operations moves from $\mathrm{GHz}$ to $\mathrm{THz}$, such as high metallic losses due to skin effect, high surface wave losses and soon [7]. Use of dielectric resonator based radiators is the easiest remedy to all these problems. It is due to the natural potential of ceramic based radiators such as, absence of metallic losses, able to create multiple mode patterns, absence of surface wave losses and easy to achieve wider impedance bandwidth [8].

Literature of antenna design at the optical spectrum is not very mature. Very less number of research articles is present in open literature. Diverse types of aerials have been structured by researchers at optical spectrum such as dipole radiator [9], Yagi-Uda radiator [10], graphene 
based radiators [11], aperture antennas [12] and so-on. However, ceramic based antennas are widely used at THz frequencies because of its inherent potential (already discussed). In 2013, Zou et.al. proposed dielectric resonator-based array at $633 \mathrm{~nm}$. It supports single frequency band and operate at the fundamental mode i.e. $\mathrm{HEM}_{11 \delta}$. It also supports the broadsided radiation pattern [13]. In the same year, Silveira et.al. presented stripline fed ceramic for Nano-photonics uses. It is also a single band antenna and operated at $193.5 \mathrm{THz}$ with broadsided far-field pattern [14]. Sethi et.al. proposed microstrip line fed equilateral triangle based ceramic antenna at $195 \mathrm{THz}$. It is designed for C-band of optical spectrum [15]. Same research group has again designed as hexagonal shaped DR for $1550 \mathrm{~nm}$ optical communication. It operates on $\mathrm{HEM}_{20 \delta}$ mode and produces end fire radiation pattern [16]. Varshney et.al. proposed a ceramic based CP radiator. In the aforementioned antenna structure, cylindrical shaped ceramic material is excited by microstrip line and operated at $195 \mathrm{THz}[17]$.

In this article, ceramic material based Nano-antenna is proposed. It is the first time, when authors are proposed for multiband application in optical spectrum. In this antenna design, square shaped slot is utilized to excite the Nano cylindrical shaped ceramic material. Because of such type of feed design, three hybrid mode patterns are excited inside the cylindrical ceramic i.e. $\mathrm{HEM}_{11 \delta}, \mathrm{HEM}_{12 \delta}$ and $\mathrm{HEM}_{11 \delta+2}$. This aerial structure supports three diverse frequency bands i.e. $117.5-140 \mathrm{THz}, 158-165.5 \mathrm{THz}$ and $175.2-190.5 \mathrm{THz}$ respectively. In order to proper understanding the working of proposed radiator, the article is divided into subsections: (i) antenna layout; (ii) its detail analysis; (iii) final outcomes; and (iv) conclusion.

\section{STRUCTURAL LAYOUT OF PROPOSED NANO ANTENNA}

Fig. 1 displays the structural layout of proposed aperture coupled ceramic based nanoantenna. In this antenna design, cylindrical shaped silicon material is used as a ceramic. Its permittivity $\left(\varepsilon_{\mathrm{r}, \mathrm{Si}}\right)$ is 11.56 . Diameter $(\mathrm{D})$ and height $(\mathrm{H})$ of cylindrical shaped silicon material is $1.02 \mu \mathrm{m}$ and $0.325 \mu \mathrm{m}$. It is located over the $\mathrm{SiO}_{2}$ substrate with the permittivity $\left(\varepsilon_{\mathrm{r}}\right)$ of 2.1 [11]. The cross-sectional area of the substrate is $4 \times 4 \mu m^{2}$. Nano metallic strip line at the bottom of the substrate is made up of a silver material. Similarly, square shaped aperture has also been etched from the silver based metallic strip over the upper part of the substrate. However, gold has better conductivity and less oxidization rate as compare to silver. But, silver is cost effective and for indoor application, it does not have instant oxidation. So, silver is the most suitable material for proposed antenna. Dispersive stuffs of 
silver material used in the proposed antenna design have been decided by Drude's model. It is simply a mathematical model and given as follow [17]:

$$
\varepsilon_{\mathrm{Ag}}=\varepsilon_{0}\left[\varepsilon_{\infty}-\frac{\mathrm{f}_{\mathrm{p}}^{2}}{\{\mathrm{f}+\mathrm{i} \gamma\}}\right]
$$

In eqn. (1), $\varepsilon_{\infty}$ (real part of dielectric constant $)=5 ; f_{P}$ (plasma frequency) $=2175 \mathrm{THz}$; and $\gamma / \pi=4.35 \mathrm{THz}$ [14]. ' $\varepsilon_{\mathrm{Ag}}$ ' and ' $\gamma$ ' is the dielectric constant of silver and collision frequency respectively. ' $\mathrm{f}$ ' and ' $\varepsilon_{0}$ ' is the operating frequency and permittivity of free space. In Fig. 1, ' $h_{1}{ }^{\prime}=0.145 \mu \mathrm{m},{ }^{\prime} h_{2}$ ' $=0.020 \mu \mathrm{m}$ and ' $h_{3}{ }^{\prime}=0.010 \mu \mathrm{m}$ are the depth of the substrate on which the silver strip placed, height of the silver strip and gap between silicon based ceramic and silver strip respectively. Width of Nano silver based strip line ' $w$ ' is $0.340 \mu \mathrm{m}$ with effective reflective index of about 1.66. All these dimensions are taken from ref. [14]. Width $\left(\mathrm{W}_{\mathrm{A}}\right)$ and length $\left(\mathrm{L}_{\mathrm{A}}\right)$ of Upper silver strip is $2.0 \mu \mathrm{m}$ and $2.5 \mu \mathrm{m}$ respectively. Edges of square aperture $\left(\mathrm{L}_{\mathrm{SA}}=\mathrm{W}_{\mathrm{SA}}\right)$ has dimension $0.5 \mu \mathrm{m}$.

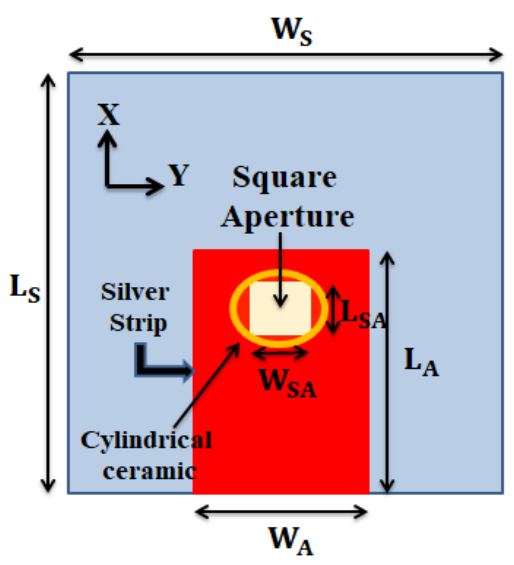

(a)

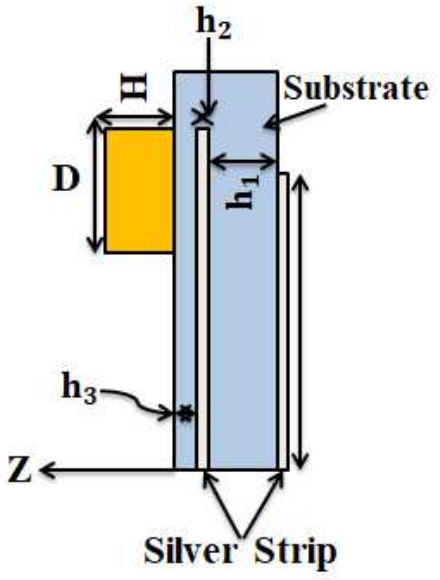

(b)

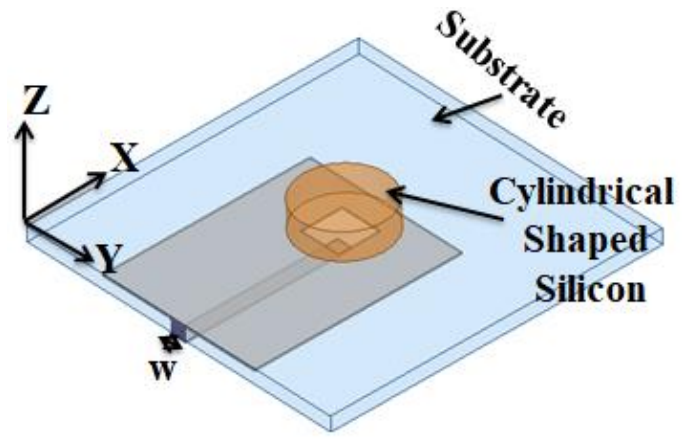

(c)

Fig. 1 Ceramic Based Nano Antenna (a) Top View (b) Side View (c) 3D View

\section{III.DETAILED ANALYSIS OF PROPOSED NANO RADIATOR}

In this subsection, theoretical in addition to mathematical investigation has been carried out with the help of Ansys HFSS EM simulator. In the proposed antenna design, two different 
resonating assemblies have been utilized: (i) aperture; and (ii) silicon based dielectric resonator. To confirm the responsibility of resonant peaks produced in the optical spectrum, Fig. 2 displays the $\left|S_{11}\right|$ variation with and without silicon based dielectric resonator. From Fig. 2, it can be observed that all three resonant peaks are due to the silicon ceramic material.

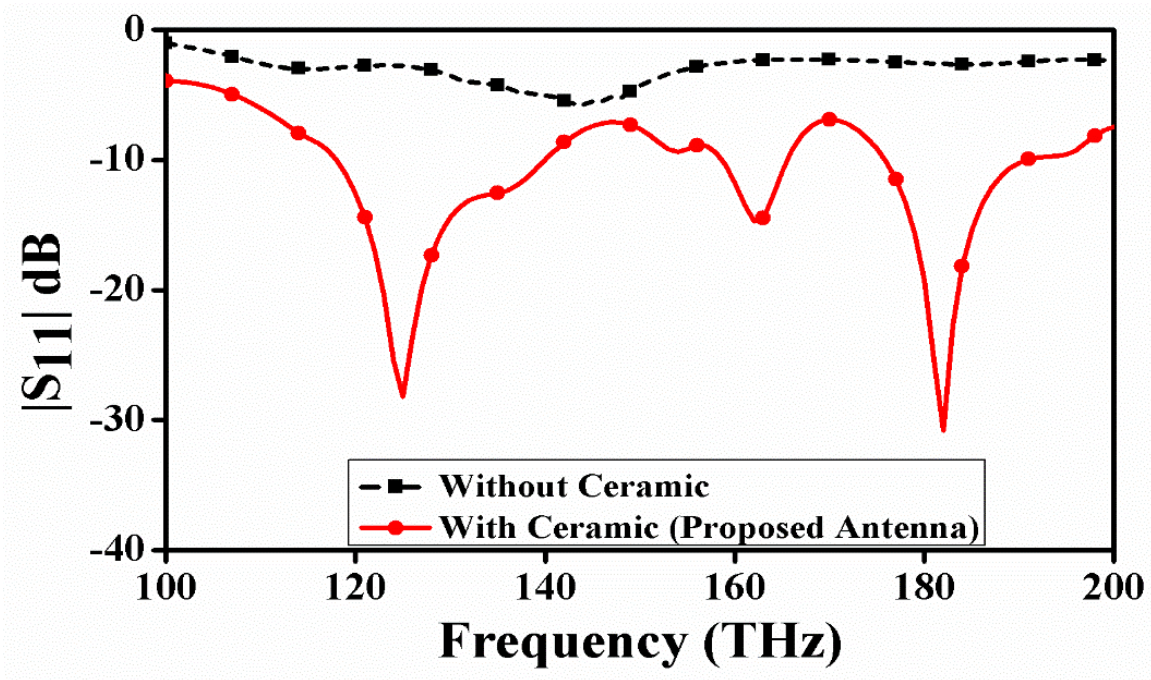

Fig. $2\left|S_{11}\right|$ variations with and without silicon based ceramic material

For understand the design methodology, the proposed nano-antenna is designed with the assistance of three steps: (i) Silicon ceramic excited with rectangular slot extended towards Y-axis; (ii) Silicon ceramic excited with rectangular aperture (slot) extended towards $\mathrm{X}$-axis; and (iii) square aperture coupled silicon ceramic. Fig. 3 shows changes in $\left|S_{11}\right|$ for silicon ceramic excited with rectangular slot extended towards $\mathrm{Y}$-axis with change in $\mathrm{L}_{\mathrm{SA}}$. From Fig. 3 , it is established that excitation with the help of Y-oriented rectangular aperture is accountable to produce two diverse modes in silicon ceramic at $125 \mathrm{THz}$ and $184 \mathrm{THz}$ respectively. For recognising the mode, Fig. 4 presents the vectored E-field orientation on silicon ceramic at $125 \mathrm{THz}$ and $184 \mathrm{THz}$ respectively. From Fig. 4, it can be said that $\mathrm{HEM}_{11 \delta}$ and $\mathrm{HEM}_{11 \delta+2}$ modes are obtained at $125 \mathrm{THz}$ and $184 \mathrm{THz}$ respectively $[18,19]$. The resonant peak due to $\mathrm{HEM}_{11 \delta}$ mode can also be confirmed mathematically by using the succeeding formulation [20]:

$$
\mathrm{f}_{\mathrm{r}, \mathrm{HEM}_{11 \delta}}=\frac{6.324 \mathrm{c}}{2 \pi \mathrm{D} \sqrt{\varepsilon_{\mathrm{r}, \mathrm{Si}}+2}}\left\{0.27+0.36\left(\frac{\mathrm{D}}{2 \mathrm{H}}\right)+0.02\left(\frac{\mathrm{D}}{2 \mathrm{H}}\right)^{2}\right\}
$$

On the other hand, the resonant peak of $\mathrm{HEM}_{11 \delta+2}$ mode can be projected mathematically as follow [21]:

$$
\mathrm{f}_{\mathrm{r}, \mathrm{HEM}_{11 \delta}+2}=1.5 \times \mathrm{f}_{\mathrm{r}, \mathrm{HEM}_{11 \delta}}
$$


In eqn. (3), the scaling factor is 1.5 because $\mathrm{HEM}_{11 \delta+2}$ mode is second higher order mode of $\mathrm{HEM}_{11 \delta}$ mode. Cylindrical shape always follow Bessel functions, so scaling factor is 1.25, 1.5 for first and second higher order mode respectively [21]. From eqn. (2) and (3), the resonant frequency of $\mathrm{HEM}_{11 \delta}$ and $\mathrm{HEM}_{11 \delta+2}$ mode is found as $124 \mathrm{THz}$ and $186 \mathrm{THz}$ respectively.

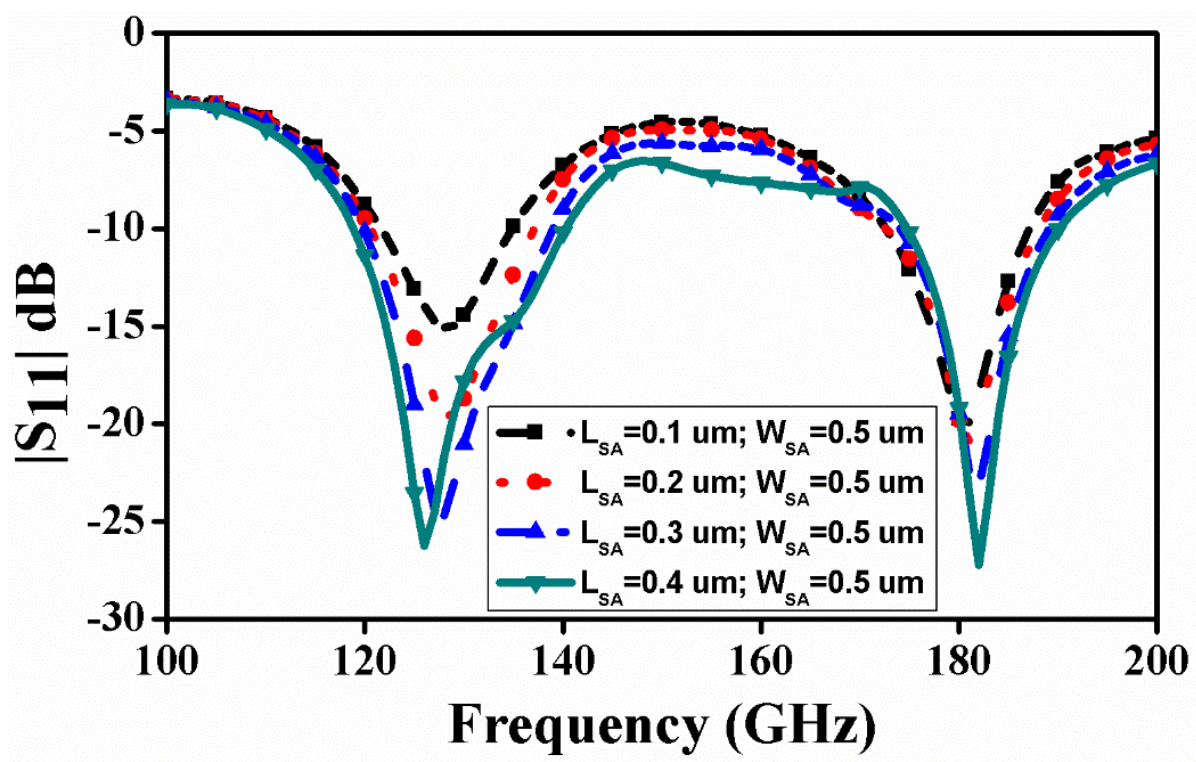

Fig. 3 Variation in $\left|S_{11}\right|$ for silicon ceramic excited with rectangular slot extended towards $Y$ axis with change in LsA

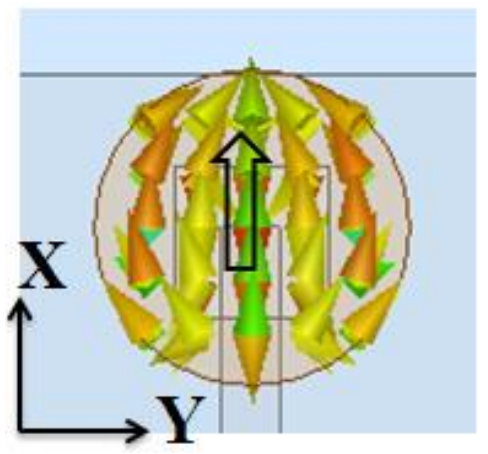

(a)

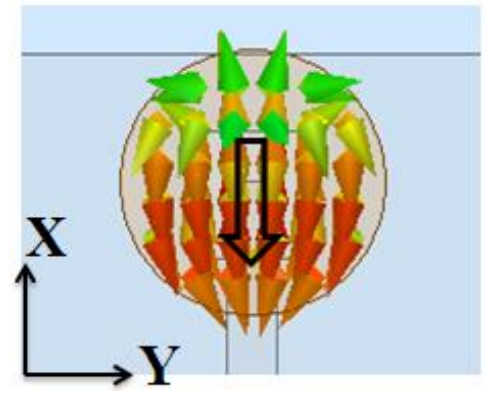

(c)

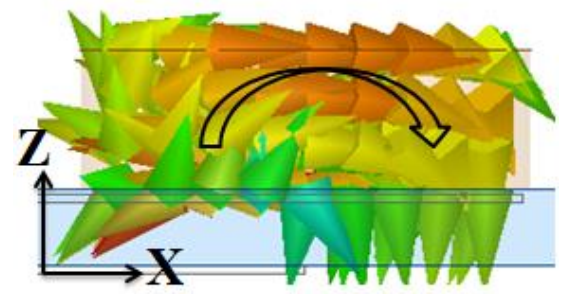

(b)

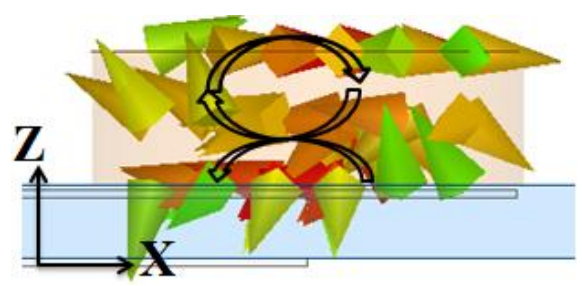

(d)

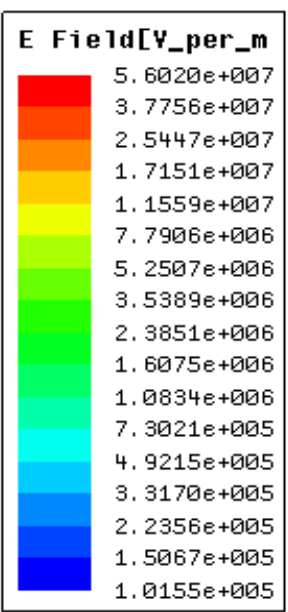

Fig. 4 E-field Variation on Si based Ceramic (a) Upper View at $125 \mathrm{THz}$ (b) Adjacent View at $125 \mathrm{THz}$ (c) Upper View at $184 \mathrm{THz}$ (d) Adjacent View at $184 \mathrm{THz}$ 
It is well known fact that if the feeding structure is act as magnetic dipole, then only $\mathrm{HEM}_{11 \delta}$ and its higher order modes are created within the Si based cylinder [20]. Fig. 5 shows electric and magnetic field distribution over the rectangular slot extended towards Y-axis at $125 \mathrm{THz}$. After seeing the field distribution i.e. electric field is maximum at the middle of aperture, it can be said that aperture supports $\mathrm{TE}_{10}$ mode, which behaves as a magnetic dipole [22]. This is the theoretical reason behind the formation of $\mathrm{HEM}_{11 \delta}$ mode. Wide slot as well as large height of cylindrical ceramic provides the appropriate boundary conditions for $\mathrm{HEM}_{11 \delta+2}$ mode [19]. Fig. 6 displays the reflection coefficient $\left(\left|S_{11}\right|\right)$ variation for silicon ceramic excited with rectangular slot extended towards $\mathrm{X}$-axis with changes $\mathrm{W}_{\mathrm{SA}}$. From Fig. 6, it is confirmed that silicon ceramic excited with rectangular aperture (slot) extended towards Xaxis supports only single frequency band centred at $160 \mathrm{THz}$. In order to find out the mode at $160 \mathrm{THz}$, Fig. 7 displays the vectored E-field orientation over the Si based ceramic at 160 THz. After seeing the Fig. 7, it can be said that $\mathrm{HEM}_{12 \delta}$ mode is accountable for resonant peak at $160 \mathrm{THz}[18]$.

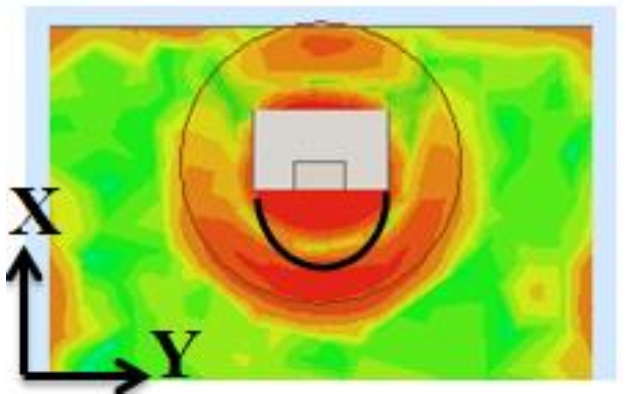

(a)

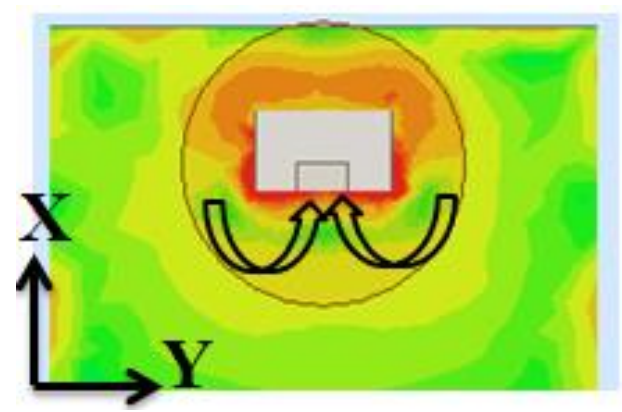

(b)

Fig. 5 Field Distribution over rectangular aperture extended towards Y-axis at $125 \mathrm{THz}$ (a) Electric Field (b) Magnetic Field

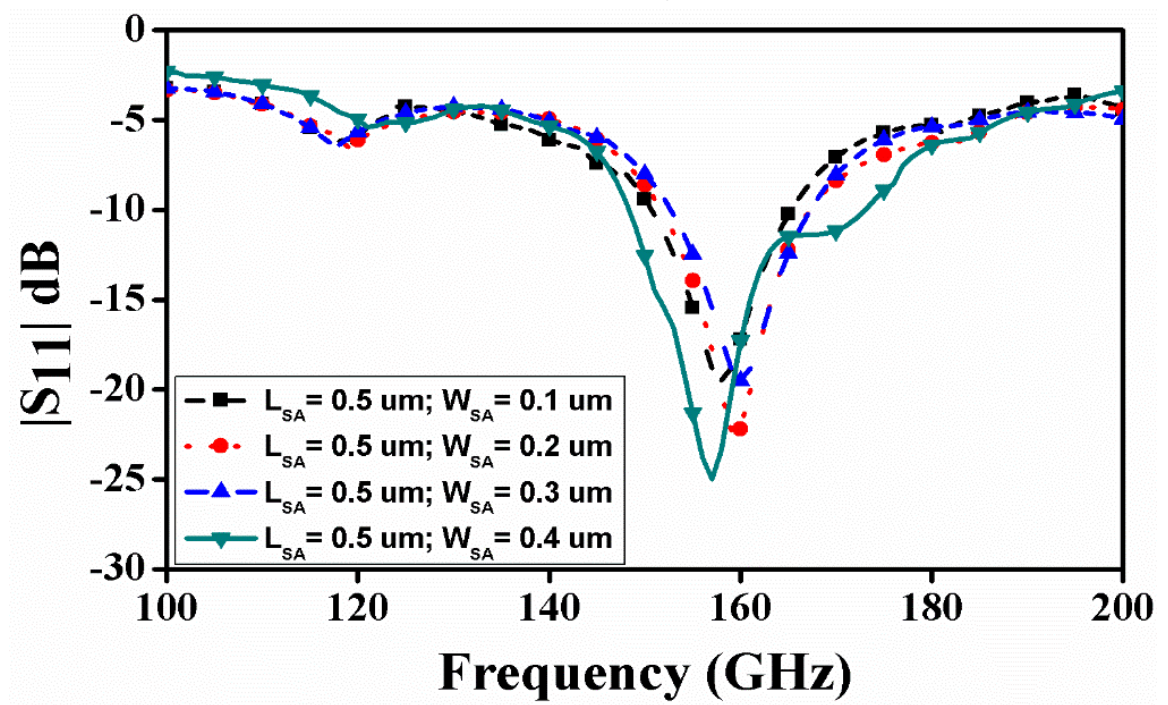

Fig. 6 Variation in $\left|S_{11}\right|$ for silicon ceramic excited with rectangular aperture (slot) extended towards $\mathrm{X}$-axis with changes $\mathrm{W}_{\mathrm{SA}}$ 


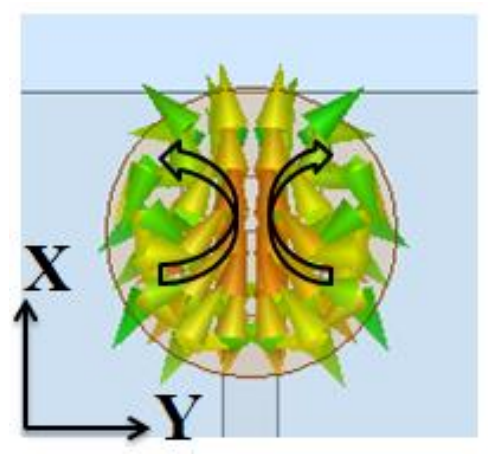

(a)

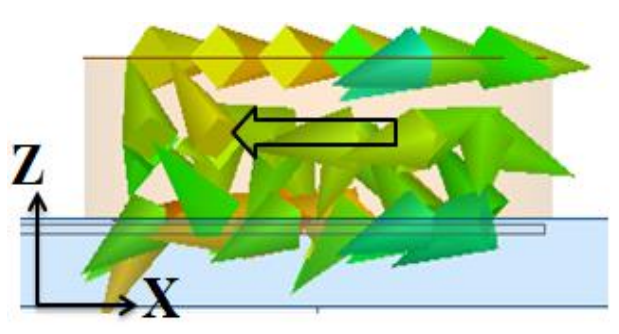

(b)

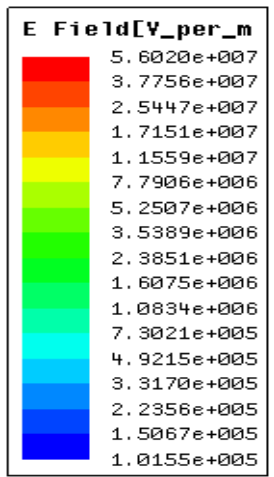

Fig. 7 E-field Variation on Si based Ceramic (a) Upper View at $160 \mathrm{THz}$ (b) Adjacent View at $160 \mathrm{THz}$

However, for resonant frequency calculation of $\mathrm{HEM}_{12 \delta}$ mode, there is no pragmatic technique existing in literature. But, its frequency can be forecast with the aid of $\mathrm{f}_{\mathrm{r}, \mathrm{HEM}_{11 \delta}}$, if the aspect ratio of ceramic material is known [23]. For the designed radiator, the aspect ratio $(\mathrm{D} / \mathrm{H})$ of $\mathrm{Si}$ based ceramic is 1.65 . For this value of aspect ratio, the scaling factor is 1.3. Therefore, mathematically, it can be written as below [23]:

$$
\mathrm{f}_{\mathrm{r}, \mathrm{HEM}_{12 \delta}}=1.3 \times \mathrm{f}_{\mathrm{r}, \mathrm{HEM}_{11 \delta}}
$$

From eqn. (4), the resonant frequency of $\mathrm{HEM}_{12 \delta}$ mode is approximately found as 161.2 $\mathrm{THz}$, which is nearer to the software generated outcome. Theoretically, excitation method must behave as electric dipole for creating $\mathrm{HEM}_{12 \delta}$ mode inside the Si based ceramic [20]. Fig. 8 displays the electric and magnetic field distribution over the rectangular slot extended towards X-axis at $160 \mathrm{THz}$. From Fig. 8, it is confirmed that behaviour of electric and magnetic field is swap in comparison to field variation at $125 \mathrm{THz}$. From the Babinet's principle, this is confirmed that rectangular aperture extended towards $\mathrm{X}$-axis behaves as an electric dipole [22]. Therefore; it generates $\mathrm{HEM}_{12 \delta}$ mode in Si based cylindrical ceramic.

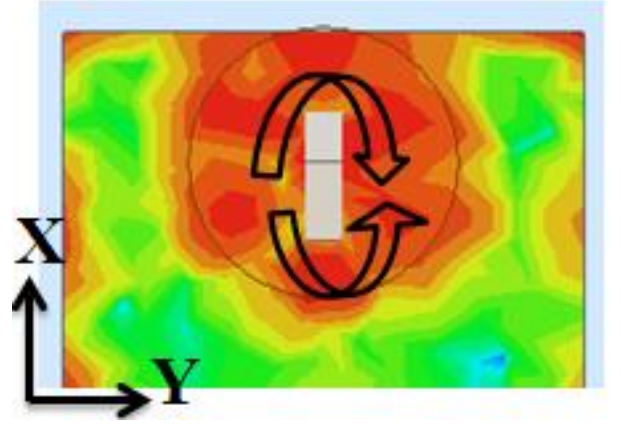

(a)

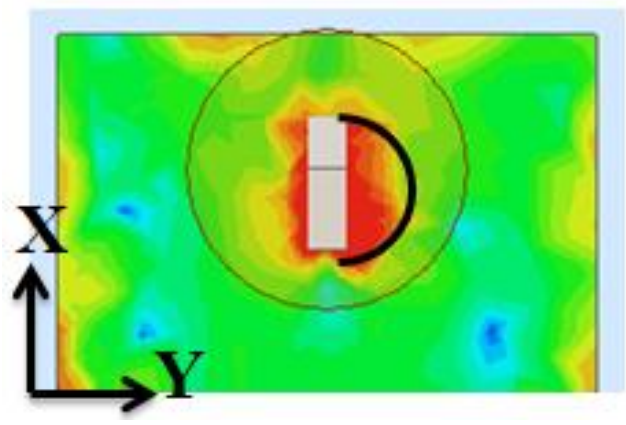

(b)

Fig. 8 Field Distribution over rectangular aperture extended towards X-axis at $160 \mathrm{THz}$ (a) Electric Field (b) Magnetic Field 
From aforementioned discussion, it is confirmed that $\mathrm{Y}$ - and $\mathrm{X}$-oriented rectangular aperture is accountable for $\mathrm{HEM}_{11 \delta} / \mathrm{HEM}_{11 \delta+2}$ and $\mathrm{HEM}_{12 \delta}$ mode respectively. In order to create all three modes in the same Si based ceramic, it is important that feed structure must behave as both electric and magnetic dipole. In order to fulfil this requirement, rectangular aperture is converted into square aperture and its $\left|S_{11}\right|$ variation is displayed in Fig. 9. Two vital comments on Fig. 9 are: (i) square shaped aperture is able to create all three mode pattern in Si based ceramic; and (ii) Optimum result is obtained at $0.5 \mathrm{um}$.

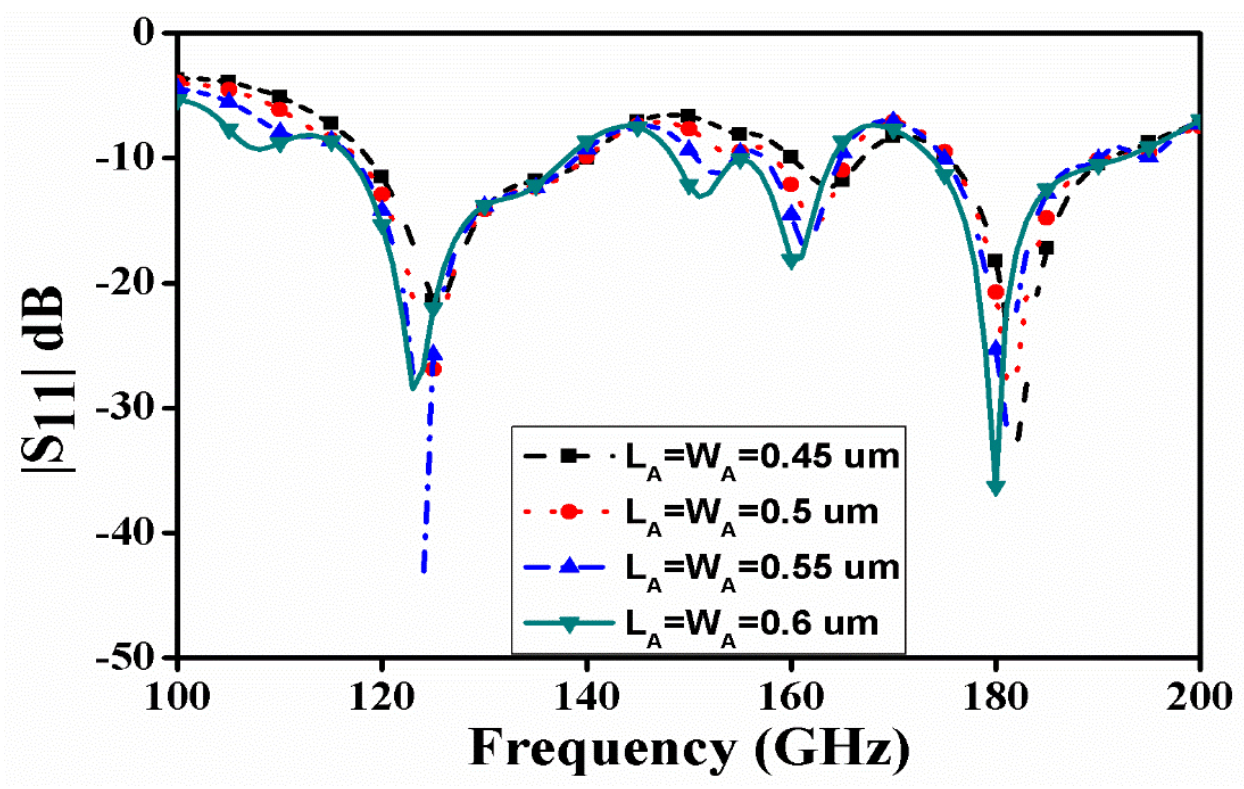

Fig. 9 Variation in $\left|S_{11}\right|$ for square aperture coupled Si based ceramic with changes in

$$
\left(\mathrm{W}_{\mathrm{SA}}=\mathrm{L}_{\mathrm{SA}}\right)
$$

\section{IV.OPTIMIZED OUTCOMES}

In this section, optimized near and far field results of proposed nano antenna are being deliberated. Fig. 10 presents the $\left|S_{11}\right|$ and gain variation of proposed ceramic based nano antenna. From Fig. 10, it is confirmed that the proposed aerial can be operated over three different frequency ranges i.e. $117.5-140 \mathrm{THz}, 158-165.5 \mathrm{THz}$ and $175.2-190.5 \mathrm{THz}$ respectively. The maximum antenna gain is about $4.0 \mathrm{dBi}$ in all three frequency bands, which is quite large in the perspective of $\mathrm{THz}$ frequency. It is actually because of the no metallic losses and high radiation efficiency in case of ceramic based antennas. Another important observation from Fig. 10 is that the gain rises as the frequency of operation increases. It is because of the existence of higher order mode. Antenna gain is proportional to the square of frequency i.e. $G \propto f^{2}[22]$. 


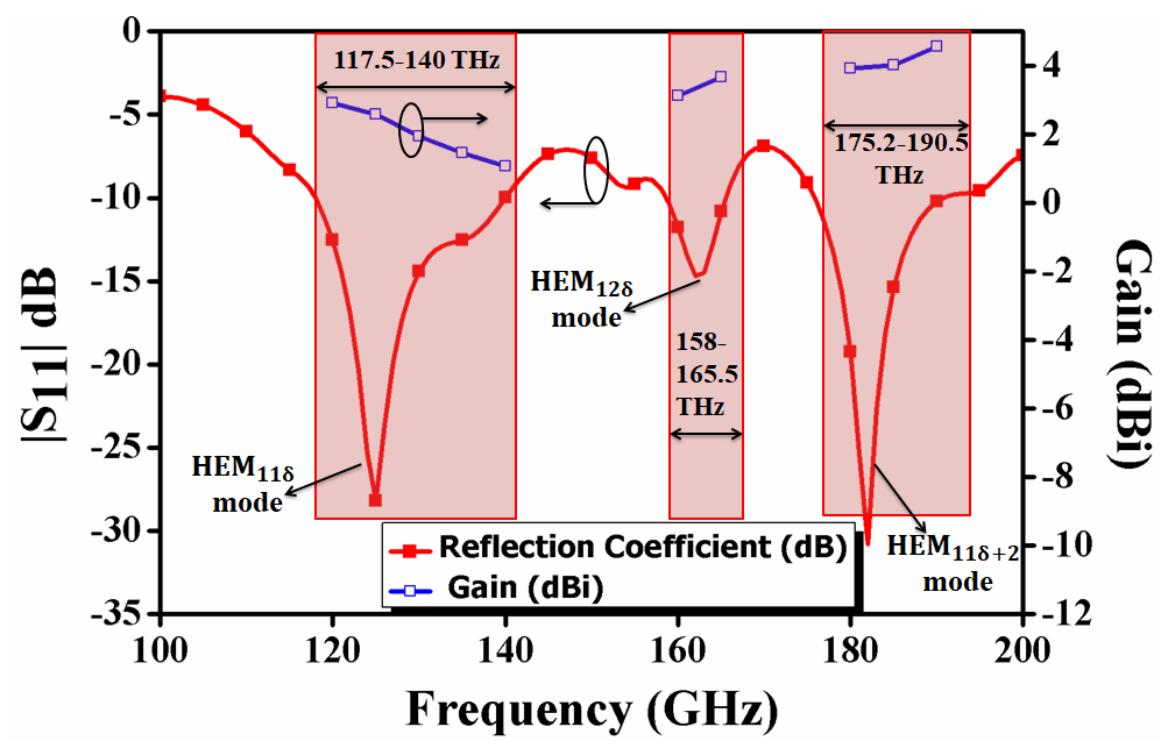

Fig. 10 Optimized $\left|S_{11}\right|$ and Gain variation of proposed ceramic based Nano Antenna

Fig. 11 shows the far-field pattern of proposed ceramic based nano antenna in two planes i.e. $\mathrm{XZ}$ and YZ plane at $125 \mathrm{THz}, 160 \mathrm{THz}$ and $184 \mathrm{THz}$ respectively. After seeing the radiation pattern, two important observations are obtained: (i) broadside radiation characteristics confirms the generation of hybrid mode at all three frequency points [20]; and (ii) cross polarization level is approx. $15 \mathrm{~dB}$ less as compare to co polarization level in both the planes, which confirms the good performance of proposed nano-antenna. Table-1 compares the performance of proposed nano antenna with other existing ceramic based nano antenna. After seeing the Table-1, it can be said that the proposed antenna offers better performance as compare to other existing aerials.

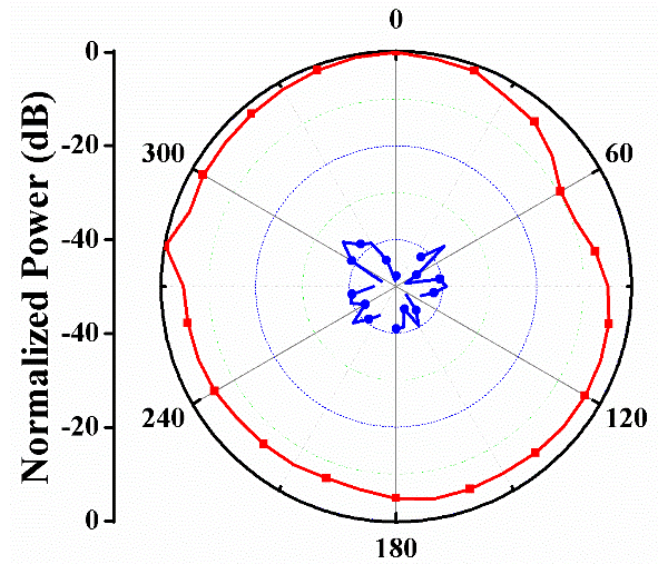

(a)

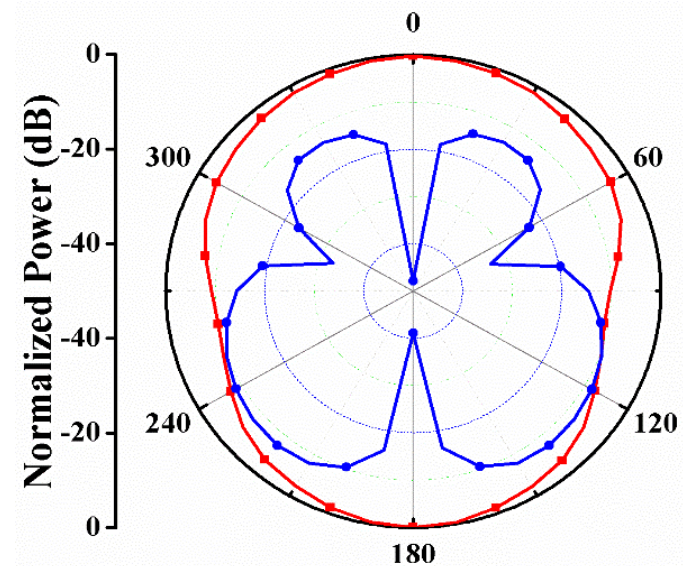

(b) 


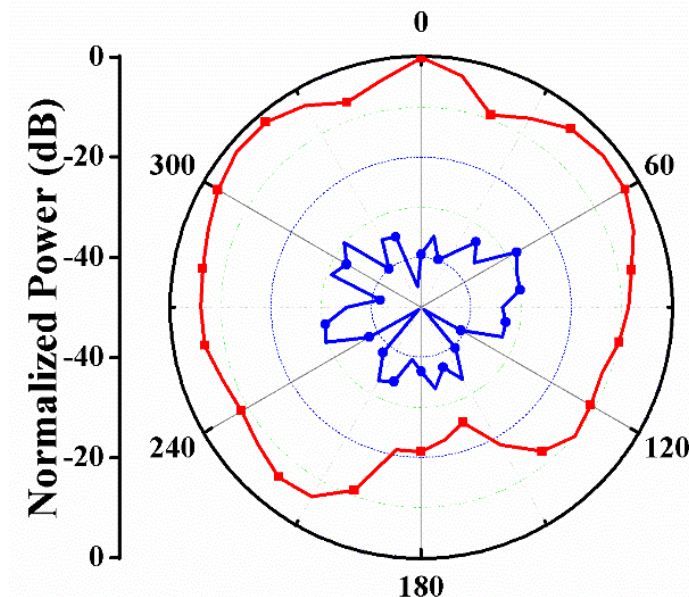

(c)

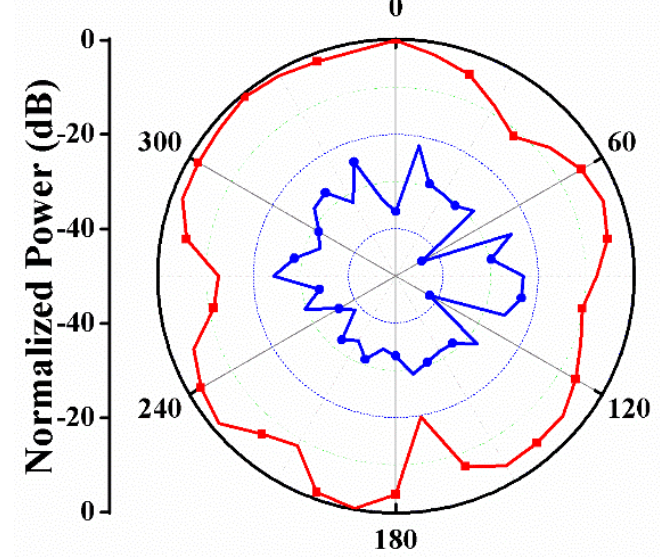

(e)

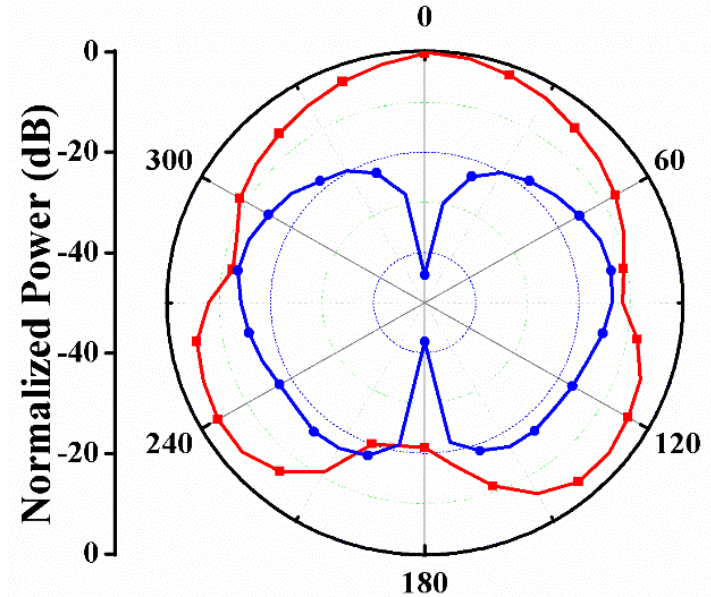

(d)

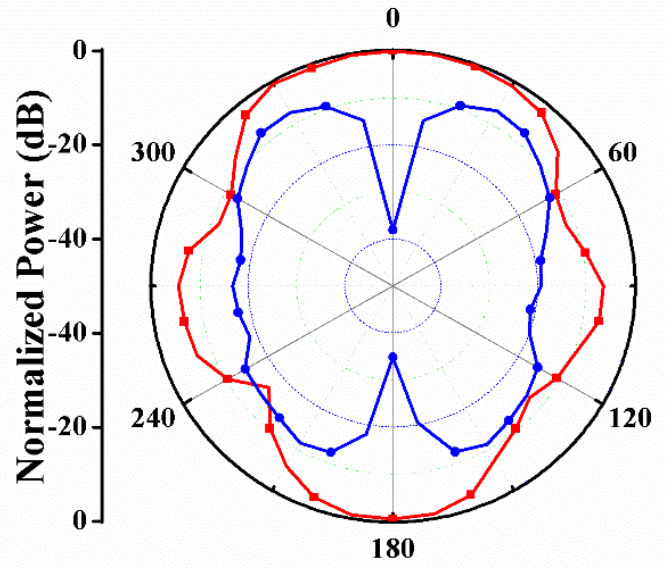

(f)

\section{$\because$ Co-pol $\rightarrow$ Cross-Pol}

Fig. 11 Radiation pattern of proposed Nano Antenna (a) XZ plane at $125 \mathrm{THz}$ (b) YZ plane at $125 \mathrm{THz}$ (c) XZ plane at $160 \mathrm{THz}$ (d) YZ plane at $160 \mathrm{THz}$ (e) XZ plane at 184 $\mathrm{THz}$ (f) YZ plane at $184 \mathrm{THz}$

Table-1 Comparison of Proposed Antenna with other existing ceramic based Nano Antenna

\begin{tabular}{|c|c|c|c|c|c|}
\hline $\begin{array}{c}\text { Shape of } \\
\text { Ceramic } \\
\text { with year }\end{array}$ & $\begin{array}{c}\text { Feed } \\
\text { Mechanism }\end{array}$ & $\begin{array}{c}\text { Operating } \\
\text { Frequency } \\
\text { Range (THz) }\end{array}$ & $\begin{array}{c}\text { Impedance } \\
\text { Bandwidth }(\%)\end{array}$ & $\begin{array}{c}\text { Gain } \\
(\mathrm{dBi})\end{array}$ & $\begin{array}{c}\text { Number of } \\
\text { Bands }\end{array}$ \\
\hline $\begin{array}{c}\text { Cylindrical } \\
(2013)[14]\end{array}$ & $\begin{array}{c}\text { Nano Strip } \\
\text { line }\end{array}$ & $185-205$ & 10.25 & 8.0 & 01 \\
\hline $\begin{array}{c}\text { Triangular } \\
(2015)[15]\end{array}$ & $\begin{array}{c}\text { Nano Strip } \\
\text { line }\end{array}$ & $192.5-197.3$ & 2.58 & Not Given & 01 \\
\hline $\begin{array}{c}\text { Hexagon } \\
(2016)[16]\end{array}$ & $\begin{array}{c}\text { Nano Strip } \\
\text { line }\end{array}$ & $190.9-198.1$ & 3.7 & Not Given & 01 \\
\hline $\begin{array}{c}\text { Cylindrical } \\
(2019)[17]\end{array}$ & $\begin{array}{c}\text { Nano Strip } \\
\text { line }\end{array}$ & $187-210$ & 11.58 & Not Given & 01 \\
\hline $\begin{array}{c}\text { Cylindrical } \\
\text { (Proposed) }\end{array}$ & $\begin{array}{c}\text { Square } \\
\text { Aperture }\end{array}$ & $\begin{array}{c}\mathbf{1 1 7 . 5 - 1 4 0} \\
\mathbf{1 5 8 - 1 6 5 . 5 /} \\
\mathbf{1 7 5 . 2 - 1 9 0 . 5}\end{array}$ & $\mathbf{1 7 . 4 7 / 4 . 6 3 / 8 . 3 7}$ & $\mathbf{4 . 0}$ & $\mathbf{0 3}$ \\
\hline
\end{tabular}




\section{CONCLUSION}

In this communication, a ceramic based Nano antenna has been designed and analysed. After doing the literature survey, authors have confirmed that it is the first time, when tri band antenna is designed for wireless photonics applications. Tri-band characteristics have been achieved by creating three different hybrid radiating modes $\left(\mathrm{HEM}_{11 \delta}, \mathrm{HEM}_{12 \delta}\right.$ and $\left.\mathrm{HEM}_{11 \delta+2}\right)$ inside the Si based ceramic with the assistance of square shaped aperture. The proposed nano antenna is operating over three frequency bands i.e. 117.5-140 THz, $158-165.5 \mathrm{THz}$ and 175.2-190.5 THz respectively. The use of ceramic material reduces the problem of quantum contacts of nano antenna. Stable radiation pattern and good value of gain $(4.0 \mathrm{dBi})$ is helpful to make the proposed antenna employable for hyper spectral imaging system $(125 \mathrm{THz})$ and VLC for wireless LAN (160/180THz) at optical spectrum.

\section{FUTURE POSSIBILITIES}

Fabrication and measurement of such type of Nano antennas is one of the future possibilities. Some fabrication methods available in literature for antennas at Nano scale i.e. ion beam milling and electron-beam lithography [12]. In built of circular polarization as well as MIMO feature with multiband characteristics is the another important future aspects.

\section{DECLARATIONS}

* Ethics approval and consent to participate: Not Applicable

* Consent for publication: I, Anand Sharma, give my consent for the publication of identifiable details, which can include photograph(s) and/or videos and/or figures and/or details within the text ("Material") to be published in the above Journal and Article.

* Availability of data and materials: Not Applicable

* Competing interests: Not Applicable

* Funding: No funds, grants, or other support was received.

* Authors' contributions: Conceptualization and Methodology [Anand Sharma]; Formal analysis and investigation: [Devendra Kumar Tripathi]; Writing - original draft preparation and Supervision: [Yogendra Kumar Prajapati]

* Acknowledgements: Not Applicable

* Disclosure of potential conflicts of interest: There are no potential conflicts of interest.

* Research involving Human Participants and/or Animals: Not Applicable

* Informed consent: Not Applicable 


\section{REFERENCES}

1. J.N. Anker, W.P. Hall, O. Lyandres, N.C. Shah, J. Zhao and R.P. V. Duyne, Biosensing with Plasmonic Nanosensors, Nature Materials 7 (2008), 442-453

2. P. Biagioni, J.S. Huang and B. Hecht, Nanoantennas for visible and infrared radiation, Report on Progress in Physics, 75 (2012), 1-40

3. A. Devilez, B. Stout and N. Bonod, Compact metallo dielectric optical antenna for ultradirectional and enhanced radiative emission, ACS Nano 4 (2010), 3390-3396

4. J. Huang, T. Feichtner, P. Biagioni P and B. Hecht, Impedance matching and emission properties of nano antennas in an optical nanocircuit, Nano Lett., 9 (2009), 1897-902

5. J. Wen, S. Romanov and U. Peschel, Excitation of plasmonic gap waveguides by nanoantennas, Opt. Express, 17 (2009), 5925-5932

6. M. Schnell, P. Alonso-González, L. Arzubiaga, F. Casanova, L.E. Hueso, A. Chuvilin and R. Hillenbrand, Nanofocusing of mid-infrared energy with tapered transmission lines Nat. Photon. 5 (2011) 283-287

7. P. Bharadwaj, B. Deutsch, and L. Novotny, Optical antennas, Advances in Optics and Photonics, 1 (2009), 438-483

8. R.K. Mongia, A. Ittipiboon and M. Cuhaci, Measurement of radiation efficiency of dielectric resonator antennas, IEEE Microw. Guid. Wave Lett., 4 (1994), 80-82

9. L. Tang, S.E. Kocabas, S. Latif, A.K. Oakaya, L.Y. Gagnon, K.C.Saraswat and D.A.B. Miller, Nanometre-scale germanium photo detector enhanced by a near-infrared dipole antenna, Nat. Photon. 2 (2008) 226-229

10. T. Kosako, H.F. Hofmann, Y. Kadoya, Directional emission of light from a nano-optical Yagi-Uda antenna, Nat. Photon. 4 (2010), 312-315

11. G. Varshney, A. Verma, V.S. Pandey, R.S. Yaduvanshi, R. Bala, A proximity coupleld wideband grapheme antenna with the generation of higher order $\mathrm{TM}$ modes for $\mathrm{THz}$ application, Opt. Mater. 85 (2018), 456-63

12. L. Novotn, N. Van Hulst, Antennas for light, Nat. Photon. 5 (2011) 83-90

13. L. Zou, W. Withayachumnankul, C.M. Shah, A. Mitchell, M. Bhaskaran, S. Sriram, C. Fumeaux, Dielectric resonator nanoantennas at visible frequencies, Opt. Express 21 (2013) 1344-1352

14. G.N. Malheiros-Silveira, G.S. Wiederhecker and H.E. Hernández-Figueroa, Dielectric resonator antenna for applications in nanophotonics, Opt. Express 21 (2013) 1234-1239

15. W.T. Sethi, H. Vettikalladi and H. Fathallah, Dielectric resonator nanoantenna at optical frequencies” Int. Conf. Inf. Commun. Technol. Res. ICTRC, (2015), 132-135 
16. W.T. Sethi, H. Vettikalladi, H. Fathallah, M. Himdi, Nantenna for standard 1550nm optical communication systems, Int. J. Antennas Propag. (2016) 1-9

17. G. Varshney, S. Gotra, J. Kaur, V. S. Pandey, R. S. Yaduvanshi, Obtaining the circular polarization in a nanodielectric resonator antenna for photonics applications, Semicond. Sci. Technol. 34 (2019), 1-8

18. D. Kajfez, A.W. Glisson, J. James, Computed modal field distributions for isolated dielectric resonators, IEEE Trans. Microw. Theory Tech., 32 (1984), 1609-1616

19. L. Guo, K. W. Leung, Y. M. Pan, Compact Unidirectional Ring Dielectric Resonator Antennas With Lateral Radiation, IEEE Trans. Antennas Propag., 63 (2015), 5334-5342

20. R.K. Mongia and P. Bhartia,, Dielectric resonator antennas-a review and general design relations for resonant frequency and bandwidth, International Journal of Microwave and Millimeter-wave Computer Aided Engineering, 4 (1994), 230-247

21. R. Garg, P. Bhartia, I. Bahl, A. Ittipiboon, Microstrip antenna design handbook, Artech House, Norwood, MA, 2001

22. C.A. Balanis, Antenna Theory: Analysis and Design, A John Wiley \& Sons, INC., Publication, $3^{\text {rd }}$ Edition, 2005

23. A. Sharma, G. Das, S. Gupta and R.K. Gangwar, Quad-Band Quad-Sense Circularly Polarized Dielectric Resonator Antenna for GPS/CNSS/WLAN/WiMAX Applications, IEEE Antennas And Wireless Propagation Letters, 19 (2020), 403-407 
Figures

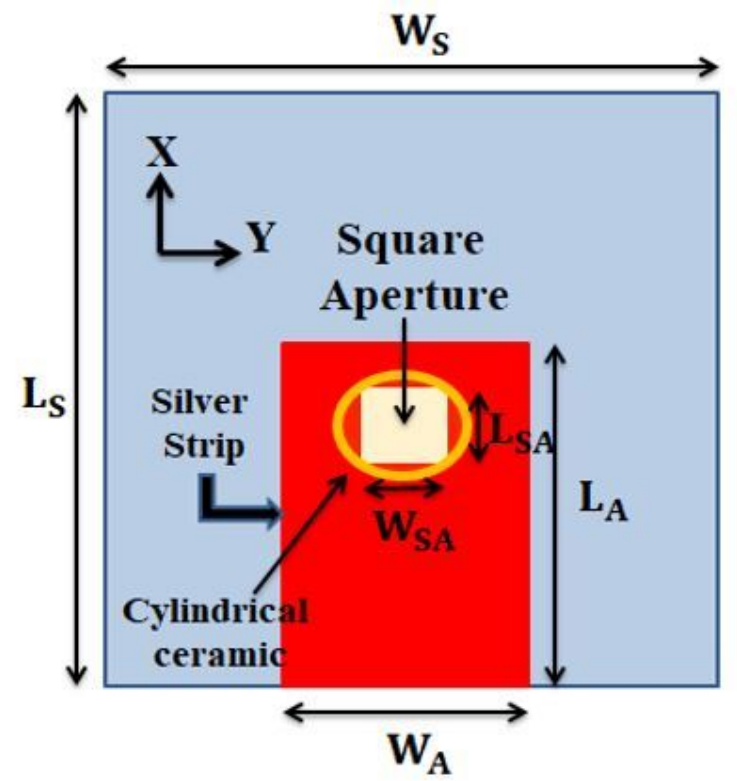

(a)

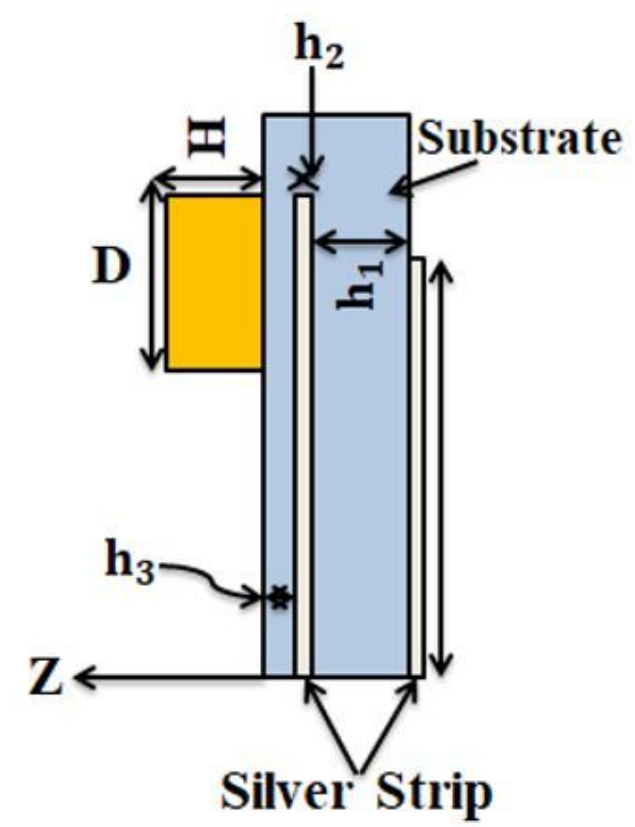

(b)

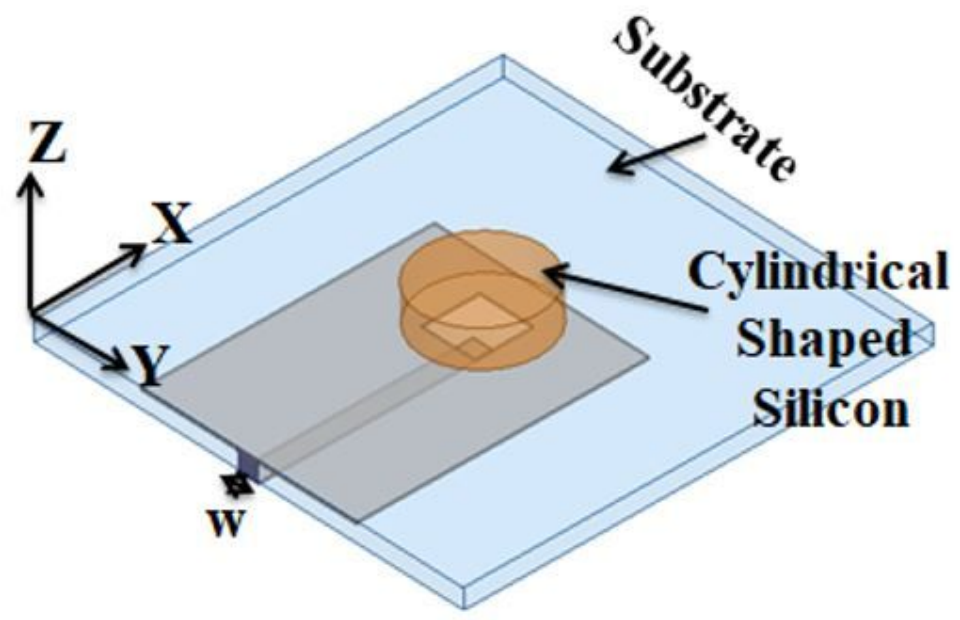

(c)

Figure 1

Ceramic Based Nano Antenna (a) Top View (b) Side View (c) 3D View 


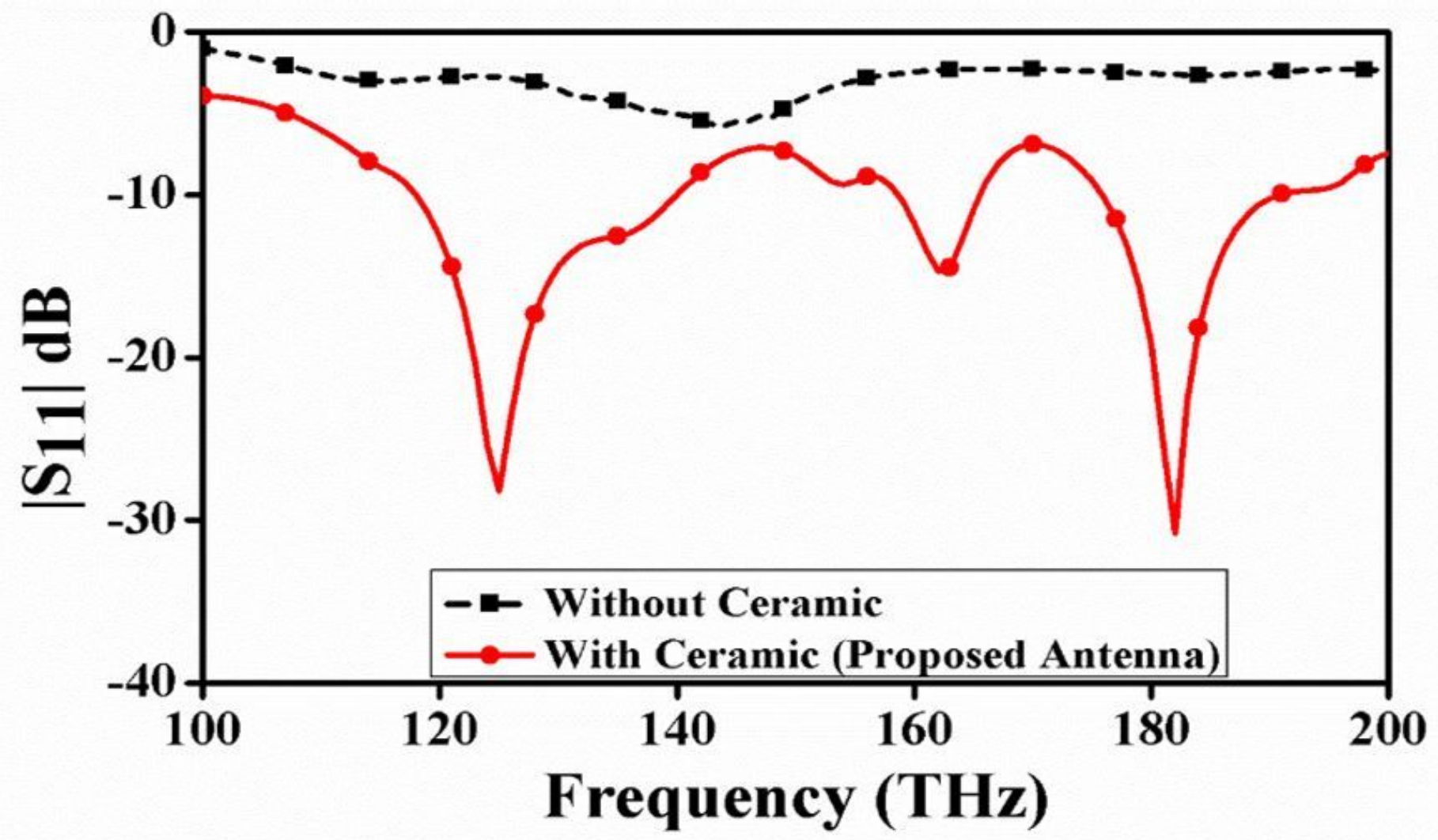

Figure 2

|S11| variations with and without silicon based ceramic material 


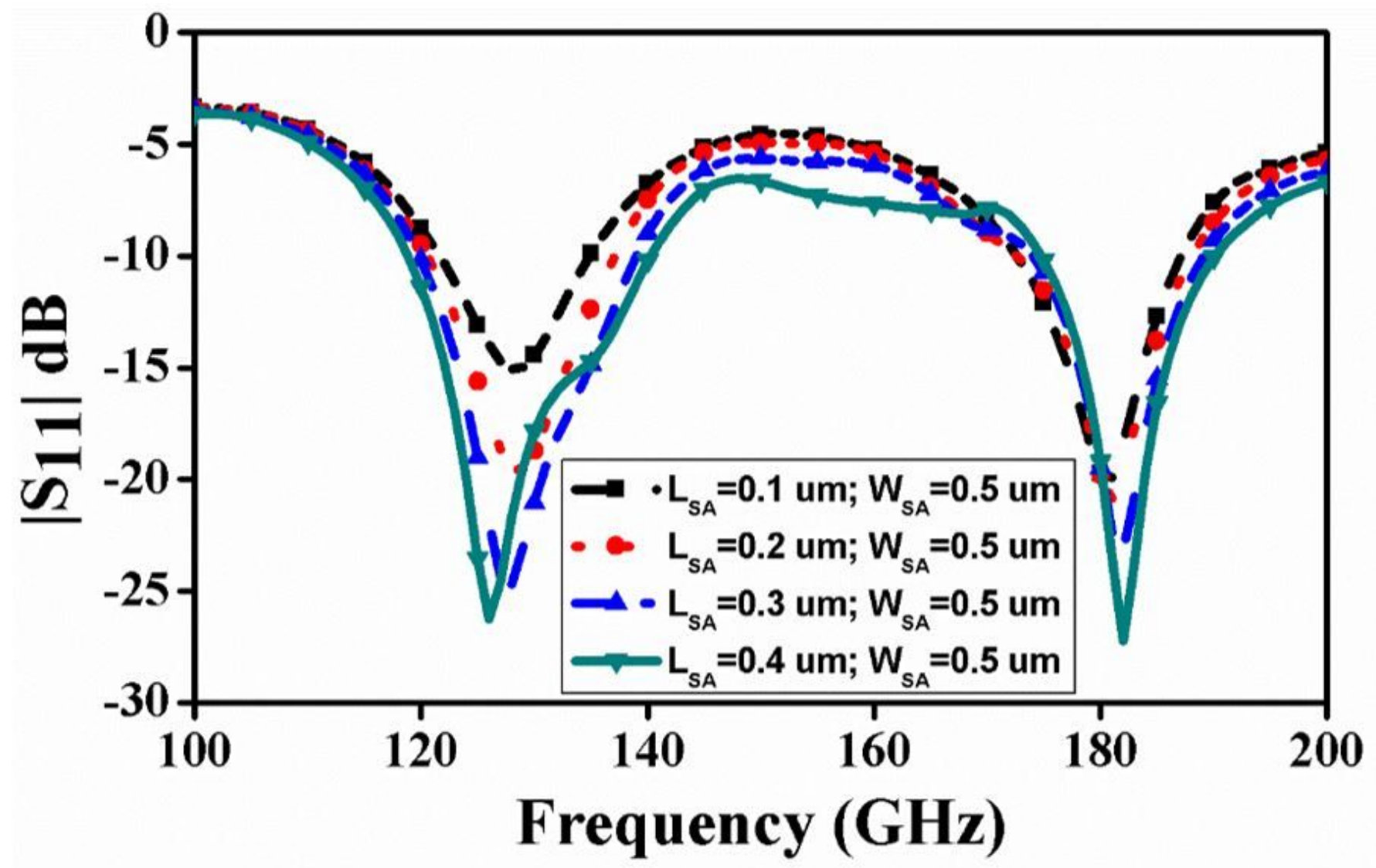

Figure 3

Variation in $|\mathrm{S} 11|$ for silicon ceramic excited with rectangular slot extended towards $\mathrm{Y}$-axis with change in LSA 


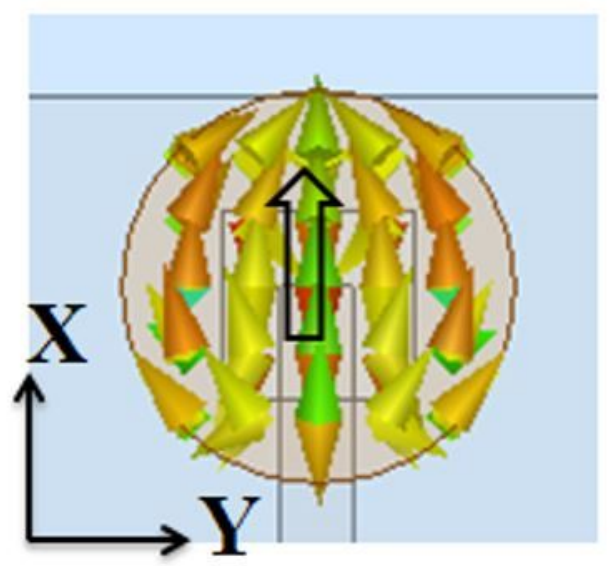

(a)

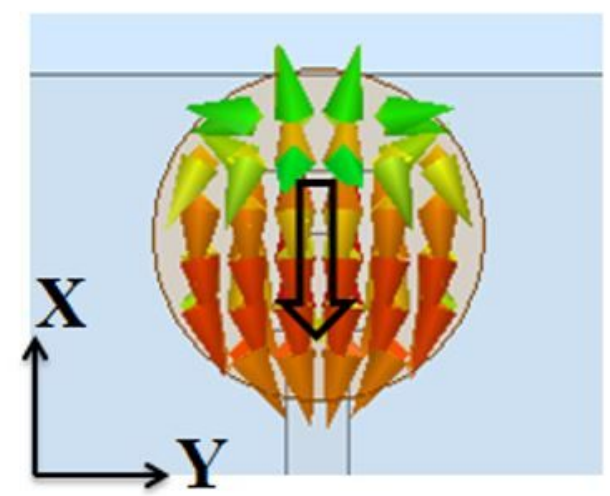

(c)

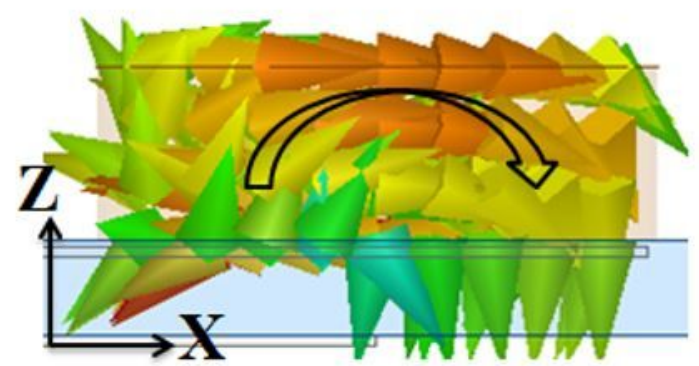

(b)

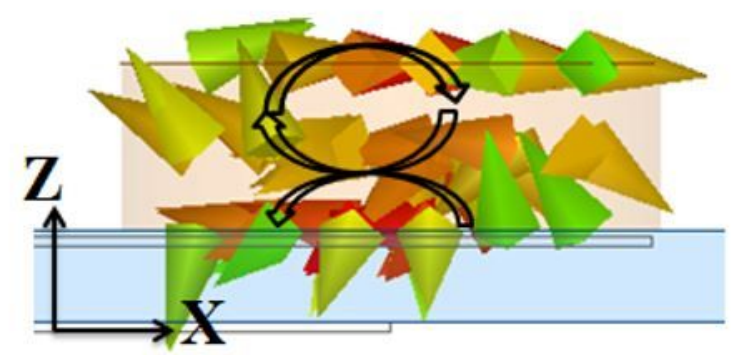

(d)

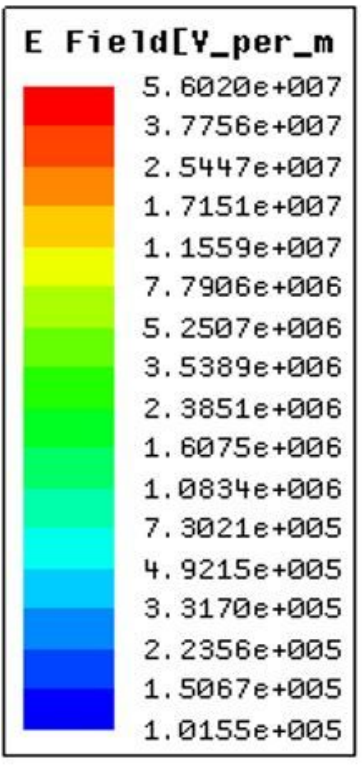

\section{Figure 4}

E-field Variation on Si based Ceramic (a) Upper View at $125 \mathrm{THz}$ (b) Adjacent View at $125 \mathrm{THz}$ (c) Upper View at $184 \mathrm{THz}$ (d) Adjacent View at $184 \mathrm{THz}$

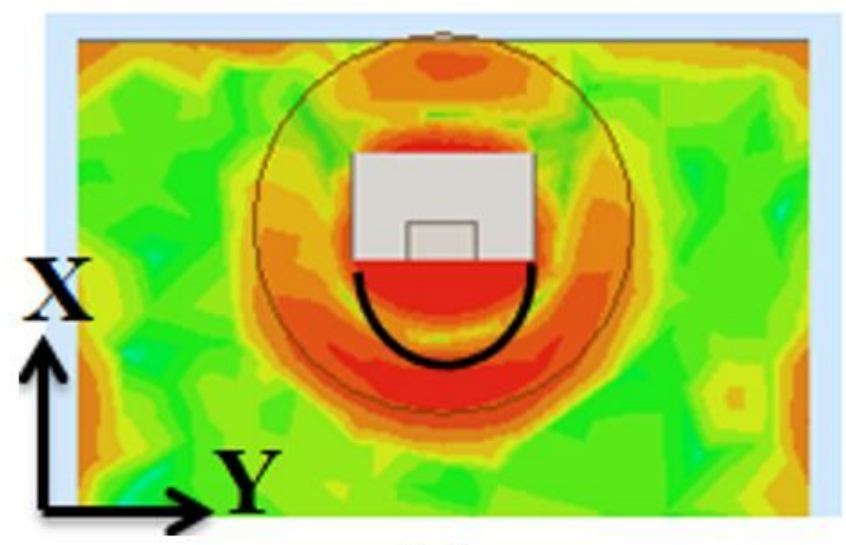

(a)

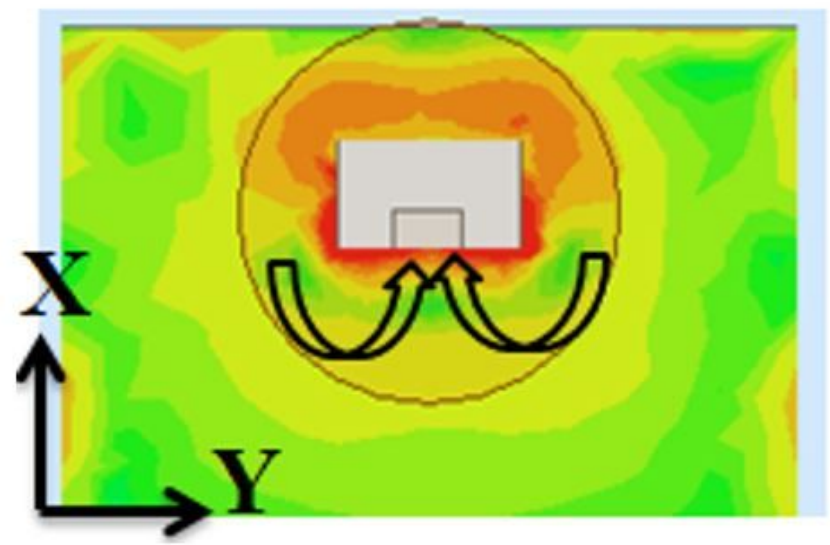

(b)

\section{Figure 5}

Field Distribution over rectangular aperture extended towards Y-axis at $125 \mathrm{THz}$ (a) Electric Field (b) Magnetic Field 


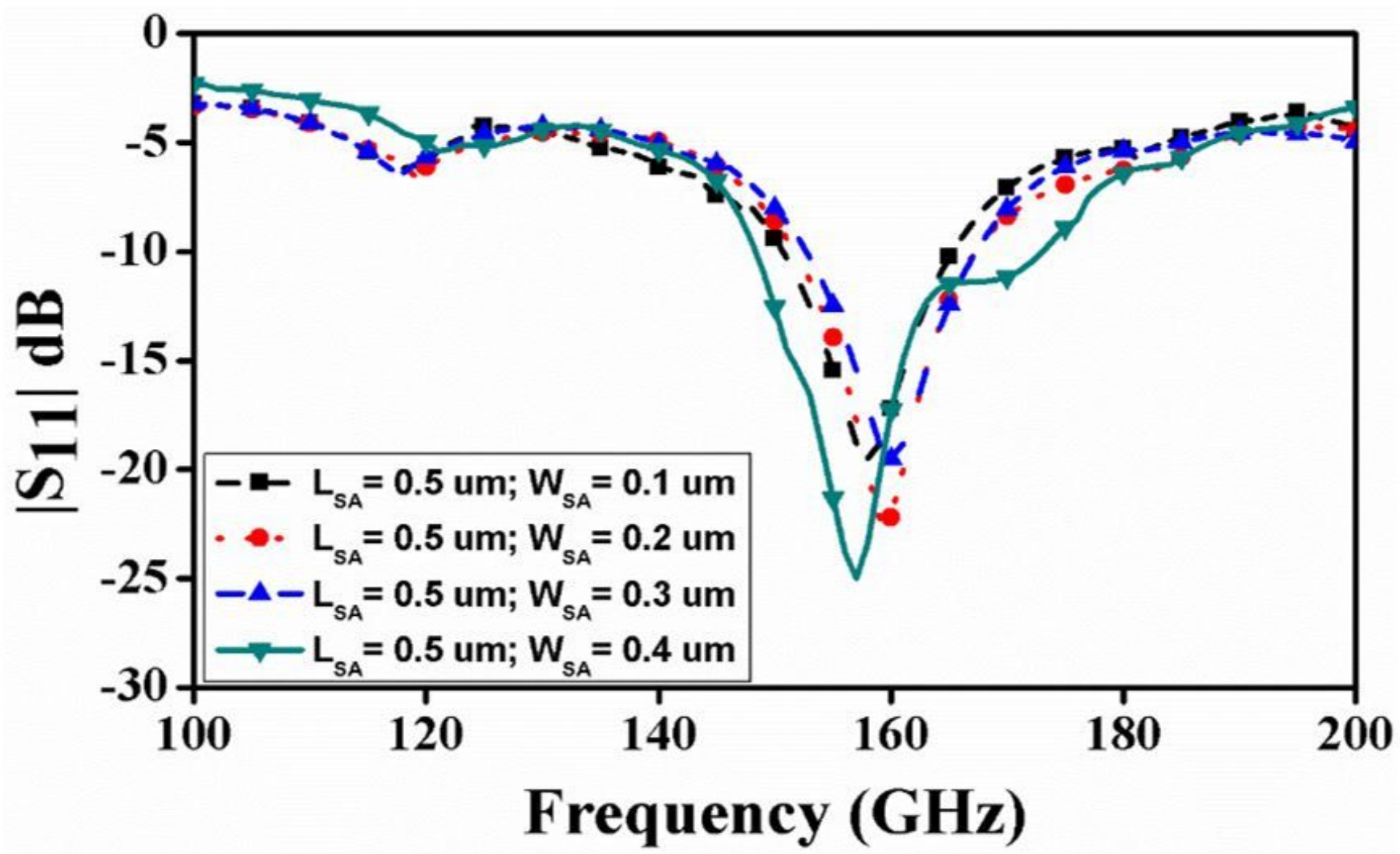

Figure 6

Variation in |S11| for silicon ceramic excited with rectangular aperture (slot) extended towards X-axis with changes WSA

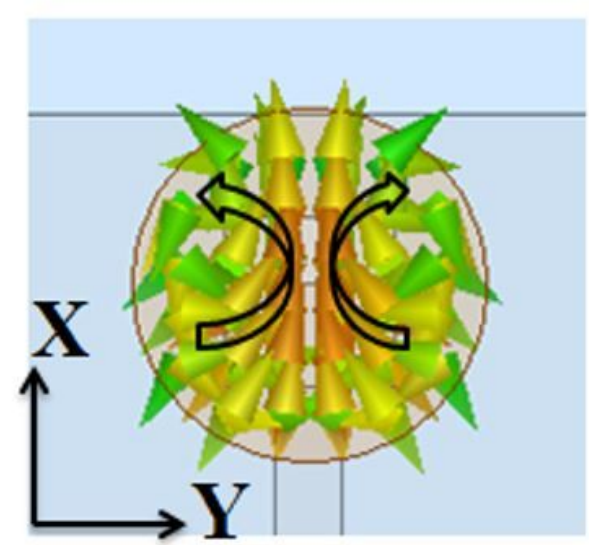

(a)

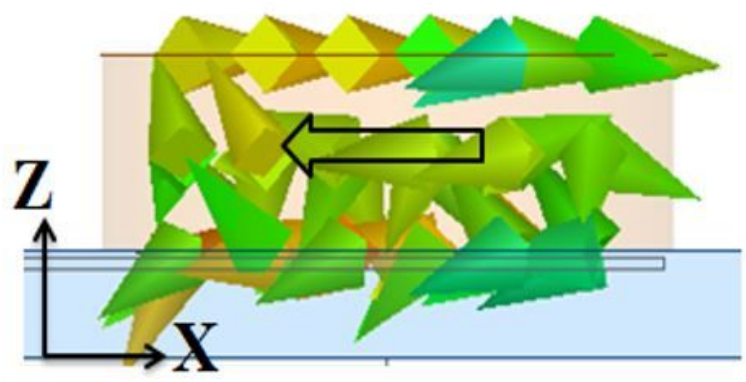

(b)

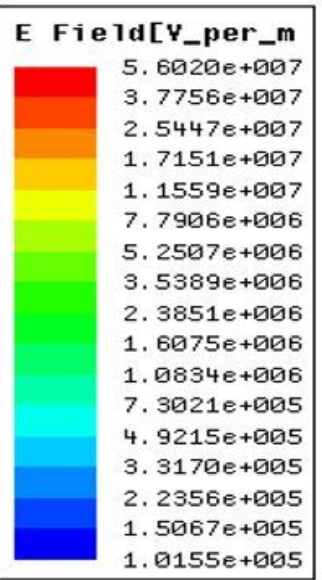

1. $0155 e+095$

Figure 7

E-field Variation on Si based Ceramic (a) Upper View at $160 \mathrm{THz}$ (b) Adjacent View at $160 \mathrm{THz}$ 


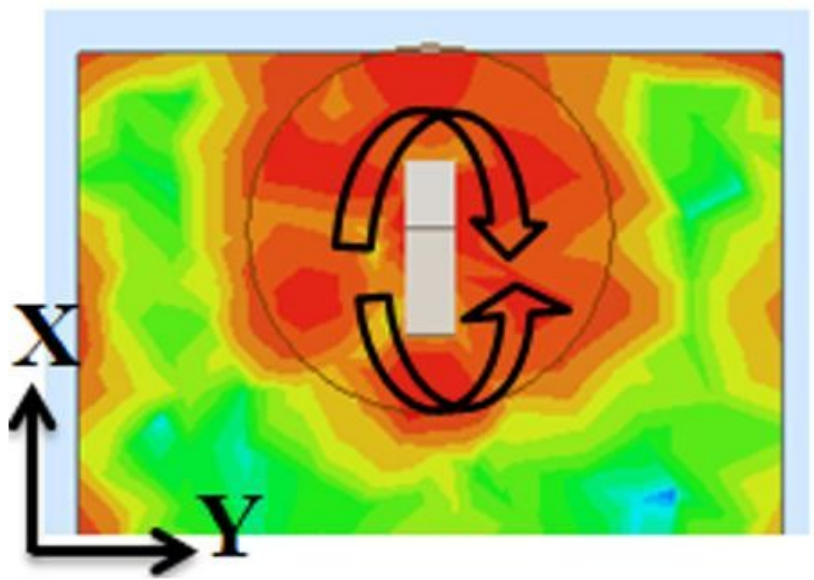

(a)

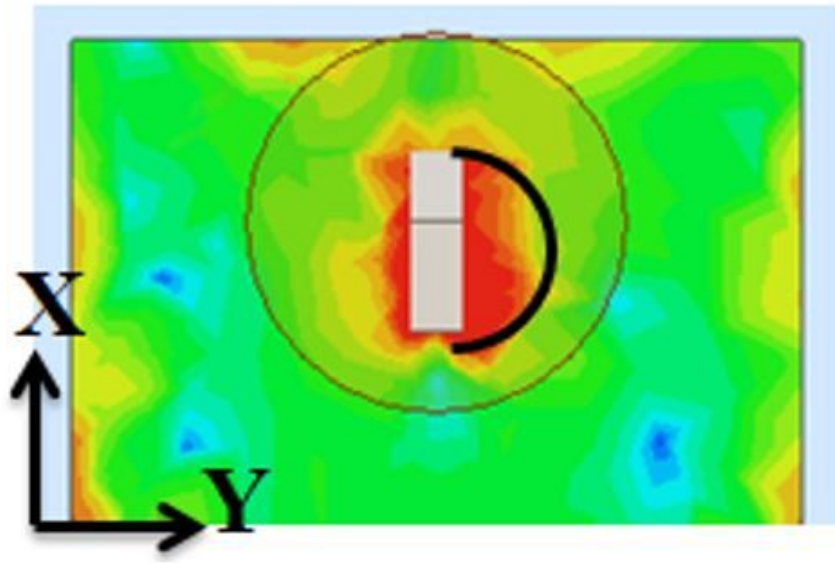

(b)

Figure 8

Field Distribution over rectangular aperture extended towards X-axis at $160 \mathrm{THz}$ (a) Electric Field (b) Magnetic Field

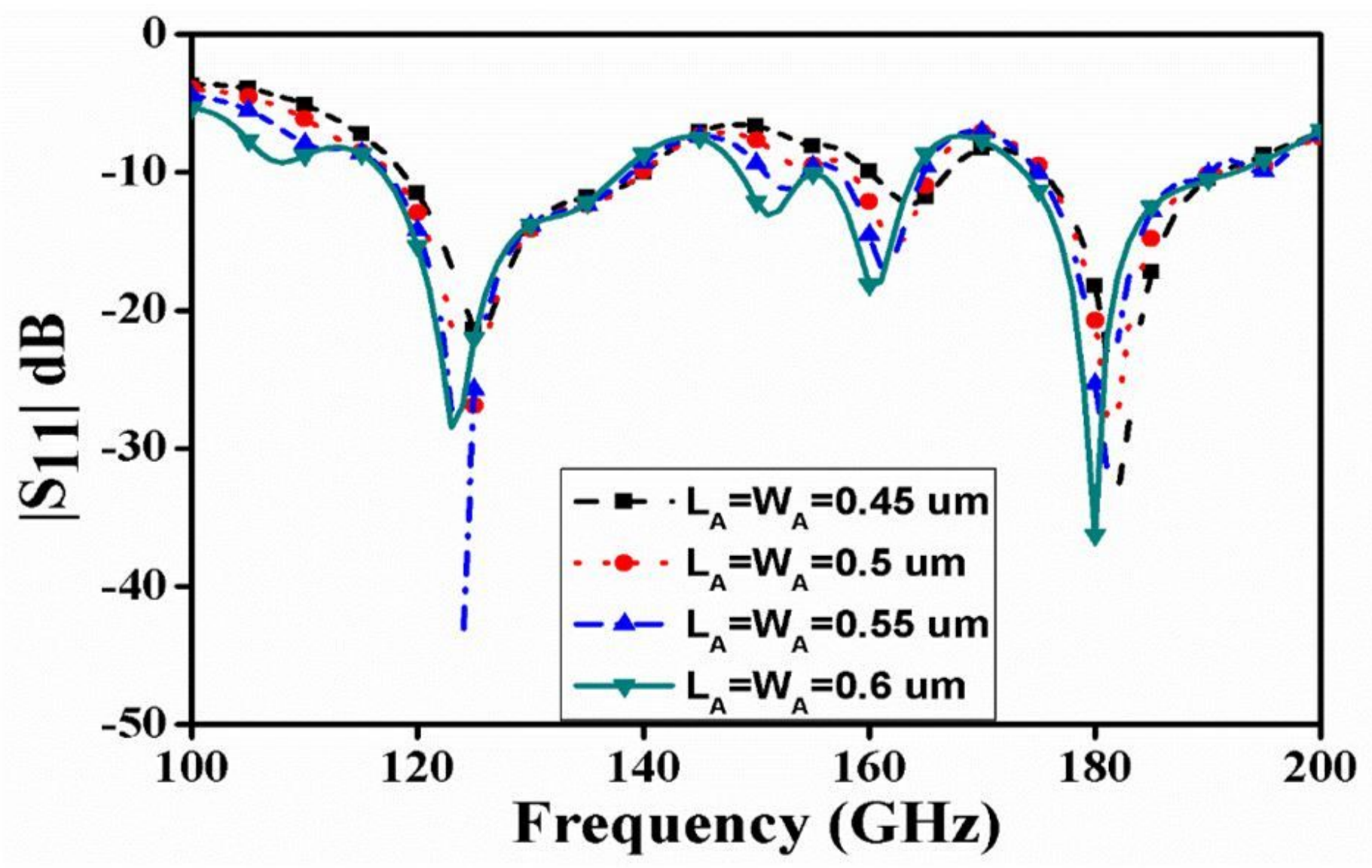

Figure 9

Variation in $|\mathrm{S} 11|$ for square aperture coupled $\mathrm{Si}$ based ceramic with changes in (WSA=LSA) 


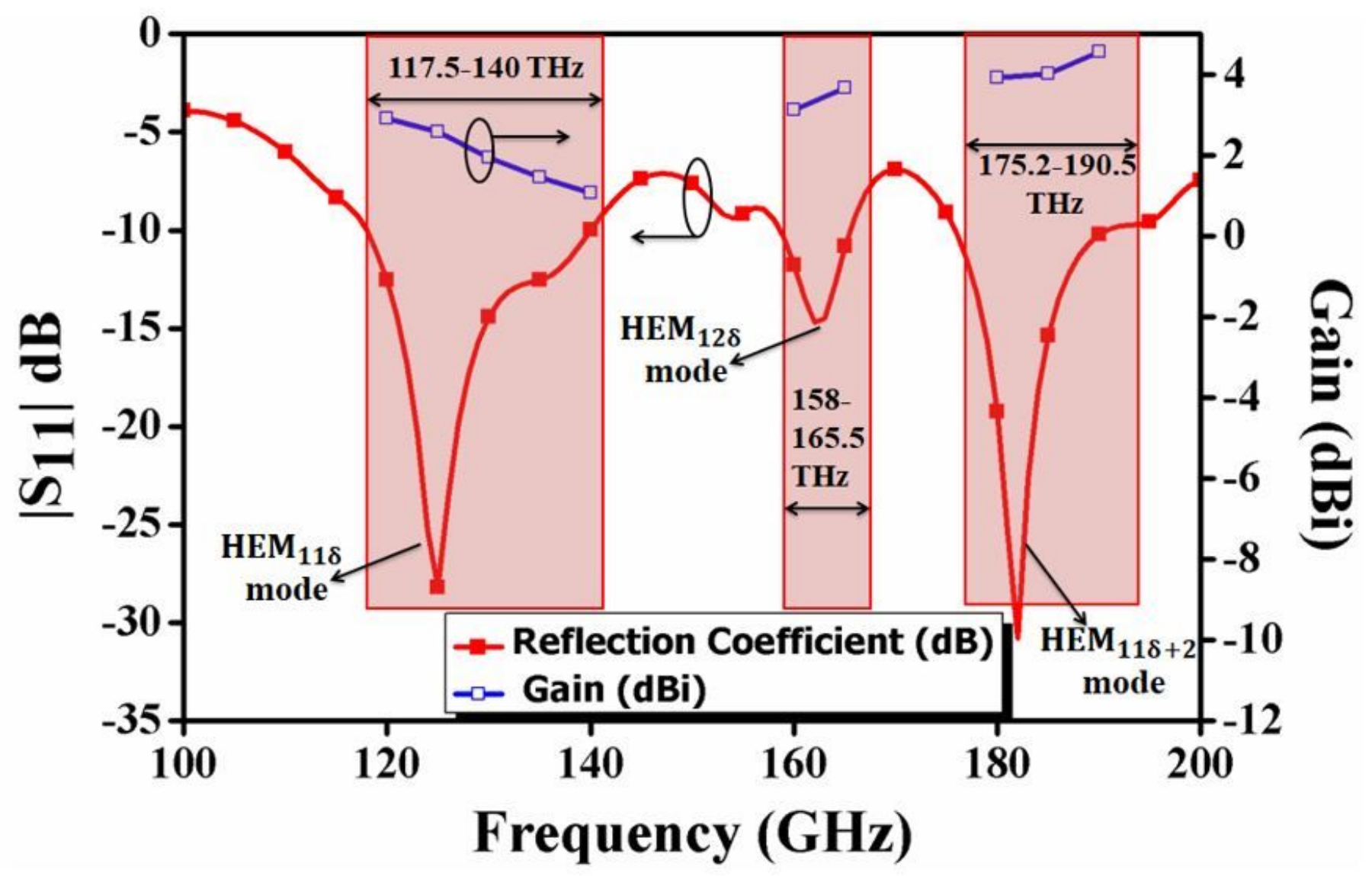

Figure 10

Optimized |S11| and Gain variation of proposed ceramic based Nano Antenna 


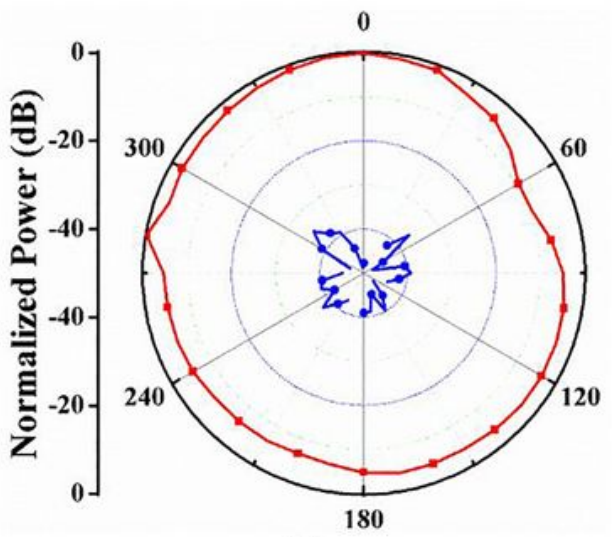

(a)

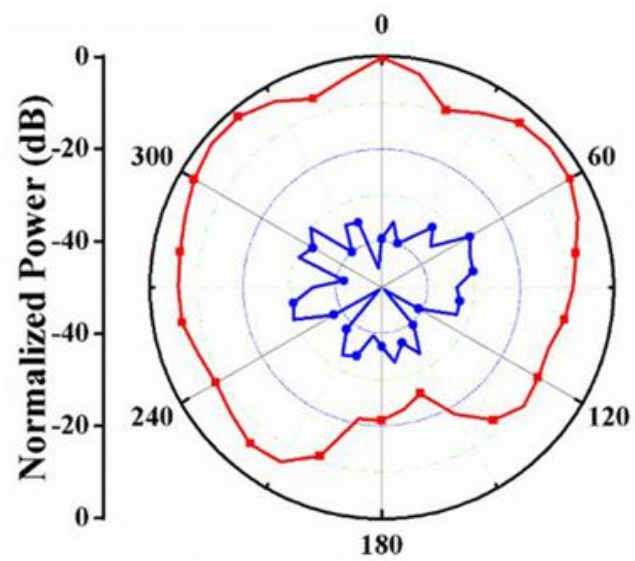

(c)

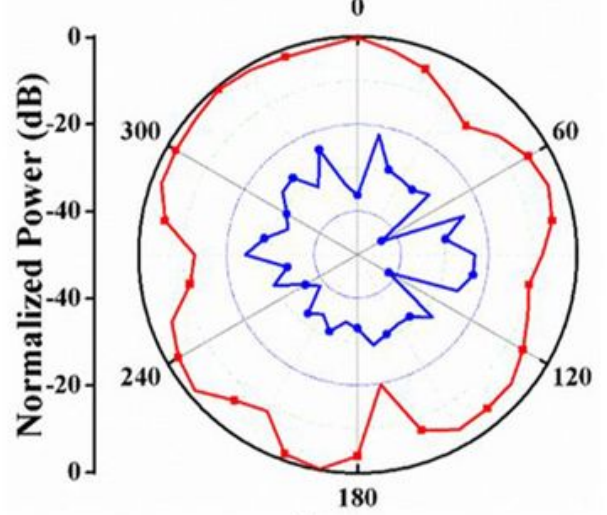

(e)

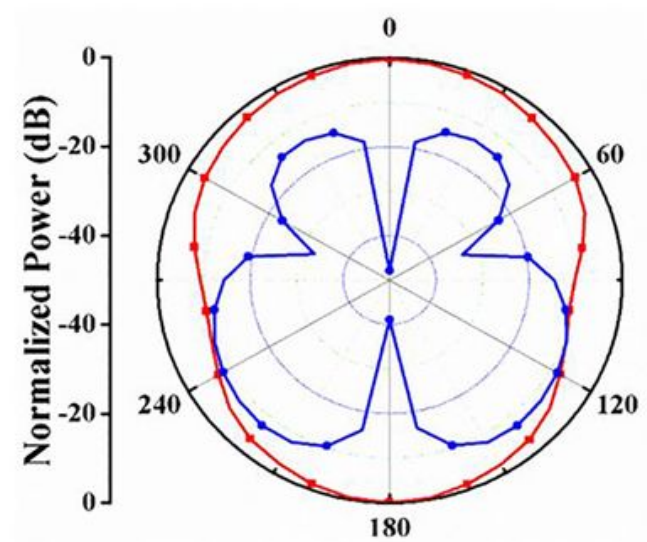

(b)

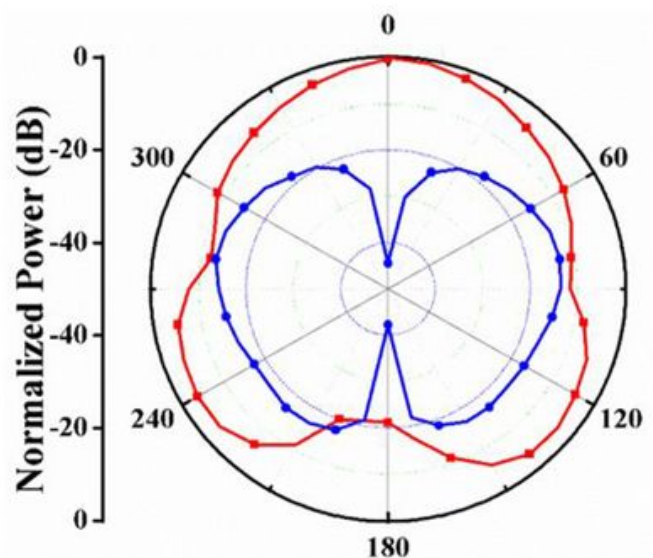

(d)

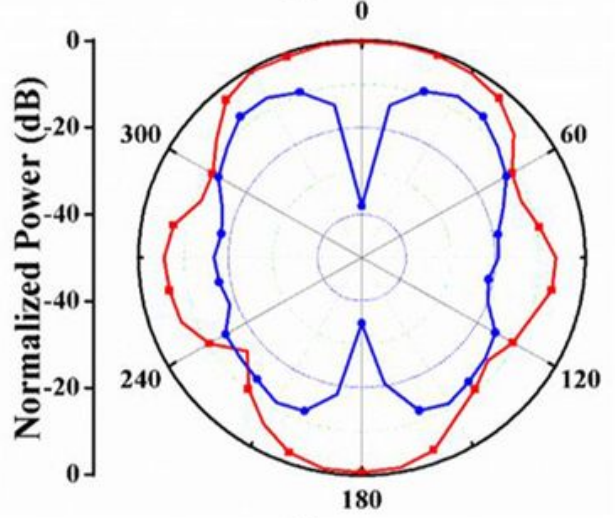

(f)

$\rightleftarrows$ Co-pol

$\rightarrow$ Cross-Pol

\section{Figure 11}

Radiation pattern of proposed Nano Antenna (a) XZ plane at $125 \mathrm{THz}$ (b) YZ plane at $125 \mathrm{THz}$ (c) XZ plane at $160 \mathrm{THz}$ (d) YZ plane at $160 \mathrm{THz}$ (e) XZ plane at $184 \mathrm{THz}$ (f) YZ plane at $184 \mathrm{THz}$ 